\title{
D-dimer as an indicator of prognosis in SARS-CoV-2 infection: a systematic review
}

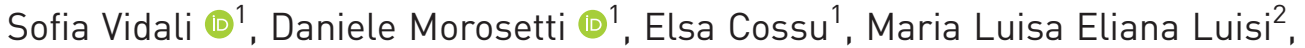 \\ Silvia Pancani ${ }^{3}$, Vittorio Semeraro ${ }^{4}$ and Guglielmo Consales ${ }^{5,6}$
}

Affiliations: 'Diagnostic and Interventional Imaging, University Hospital Policlinico Tor Vergata, Rome, Italy. ${ }^{2}$ Metabolism and Nutrition Unit, IRCCS Fondazione Don Carlo Gnocchi, Florence, Italy. ${ }^{3}$ Witheca, Witapp srl, Florence, Italy. "Diagnostic and Interventional Imaging. Santissima Annunziata Hospital, Taranto, Italy. ${ }^{5}$ Anesthesiology and Resuscitation, Santo Stefano Hospital, Prato, Italy. ${ }^{6}$ Anesthesiology and Resuscitation, Azienda USL Toscana Centro, Florence, Italy.

Correspondence: Maria Luisa Eliana Luisi, IRCCS Fondazione Don Carlo Gnocchi, Via di Scandicci 269, 50143 Florence, Italy. E-mail: mleluisiamleluisi.it

\section{ABSTRACT}

Background: Severe acute respiratory syndrome coronavirus 2 (SARS-CoV-2) stimulates pro-thrombotic changes. This, combined with its tropism for endothelium and lung structures, may explain its association with thrombotic events, reduction of pulmonary gas exchange, acute respiratory distress syndrome (ARDS) and a composite end-point (intensive care unit, invasive ventilation, death). This study aims to highlight the correlation between elevated D-dimer (an indirect thrombosis marker) and the increased rate of poor prognosisassociated conditions, and to introduce D-dimer-labelled anticoagulant administration as a potentially useful tool to prevent complications and positively influence coronavirus disease 2019 (COVID-19) course.

Methods: An online database search (PubMed, Google Scholar, Scopus, Web of Science and Cochrane) was performed between 13 March and 10 April 2020. The most relevant keywords were "D-dimer", "SARS-CoV-2", "COVID-19", "thrombosis" and "ARDS". Selection was independently conducted by three reviewers. References and previews of accepted articles were evaluated. Data inclusion/extraction inaccuracy was limited by the work of three reviewers. Selection bias reduction was addressed by thoughtfully designing the search protocol. Quality assessment was performed with the Newcastle-Ottawa Scale. The systematic review protocol was not registered because we anticipated the very limited available evidence on the topic and due to the urgency of the study.

Results: 16 studies were evaluated. Good-quality criteria were reached in 13 out of 16 studies. D-dimer was increased and significantly higher in COVID-19 patients compared with healthy controls, in COVID-19 patients with severe disease or a composite end-point compared with non-severe disease, in ARDS compared with nonARDS patients and in deceased ARDS patients compared with ARDS patients who survived (all $\mathrm{p}<0.001$ ). COVID-19 patients treated with anticoagulants demonstrated lower mortality compared with those not treated $(\mathrm{p}=0.017)$.

Conclusions: Correlations exist between COVID-19 infection, severe elevation of D-dimer levels, and increase in the rate of complications and composite end-point. The appropriateness of early and continuous D-dimer monitoring and labelled anticoagulation as management tools for COVID-19 disease deserves accurate investigation, to prevent complications and reduce interventions.

@ERSpublications

SARS-CoV-2 induces thrombotic changes and intense D-dimer elevation, possibly causing gas exchange reduction, ARDS and a composite end-point (ICU, invasive ventilation, death). Monitoring D-dimer and labelled anticoagulants might improve prognosis. https://bit.ly/3fcYqpx

Cite this article as: Vidali S, Morosetti D, Cossu E, et al. D-dimer as an indicator of prognosis in SARS-CoV-2 infection: a systematic review. ERJ Open Res 2020; 6: 00260-2020 [https://doi.org/10.1183/ 23120541.00260-2020].

Received: 7 May 2020 | Accepted after revision: 18 May 2020

Copyright $\odot$ ERS 2020. This article is open access and distributed under the terms of the Creative Commons Attribution Non-Commercial Licence 4.0. 


\section{Introduction}

In December 2019, rapidly expanding pneumonia clusters of unknown aetiology were detected in the Chinese city of Wuhan, capital of Hubei province. On 9 January 2020, a novel coronavirus, severe acute respiratory syndrome coronavirus 2 (SARS-CoV-2), was declared responsible for the outbreak of the disease, then named coronavirus disease 2019 (COVID-19) [1-3]. The number of COVID-19 diagnoses grew rapidly, with fast global spreading of disease: on 11 March 2020, the World Health Organization declared a pandemic state [3, 4]. By 14 April 2020, 1844863 confirmed cases and 117021 deaths were registered [5]. SARS-CoV-2 represents the third coronavirus-mediated threat to global health of the past decades, after SARS-CoV and Middle East respiratory syndrome coronavirus [6-9].

SARS-CoV-2 is transmitted through respiratory droplets and enters target cells through the angiotensin-converting enzyme 2 (ACE2) receptor [10, 11]. After an incubation of 2-14 days, a symptomatic phase may manifest, with fever, short breath, coughing and possible progression to pneumonia, severe respiratory dysfunction and global deterioration. Disease assessment and monitoring is performed, together with serological testing, using plain chest computed tomography (CT) scans, showing bilateral abnormalities (ground-glass, interstitial involvement, crazy paving) in $\geqslant 75 \%$ of cases [12].

Severe disease is associated with conditions such as acute respiratory distress syndrome (ARDS) and with laboratory abnormalities including leukopenia, thrombocytopenia and hypercoagulative state with D-dimer elevation [2]. Among the factors associated with a composite end-point (CEP) (defined as intensive care unit (ICU) access, invasive ventilation and death) are comorbidities, older age and ARDS [2]. Similarly, the procoagulant state, particularly D-dimer elevation, has demonstrated an association with ARDS and a CEP [2].

The aim of this study was to analyse SARS-CoV-2 coagulation deregulatory effects, especially referring to D-dimer elevation and its correlation with thrombotic events, ARDS and a CEP.

\section{Materials and methods}

Data sources and searches

An online database search on PubMed, Google Scholar, Scopus, Web of Science, and Cochrane was performed from 13 March 2020 to 10 April 2020. The keywords and their variants (differently combined) used for the search were "COVID-19", "2019-nCoV", "2019 novel coronavirus", "SARS-CoV-2", "D-dimer", "coagulation", "hypercoagulative state", "laboratory analysis", “ARDS”, "haemostasis", "thrombosis", "pulmonary embolism", "disseminated intravascular coagulation (DIC)", "heparin" and "anti-coagulation".

\section{Study selection}

The inclusion criteria were as follows: COVID-19 populations, presence of laboratory test values including coagulation parameters (D-dimer specifically), and D-dimer correlation with study population characteristics. The exclusion criteria were: patients included in the study who were aged $<14$ years, absence of $\mathrm{D}$-dimer values, conference abstracts, commentary abstracts, letters to authors, articles written with a non-Arabic alphabet with no available translation, and case reports. Pre-published previews of accepted articles were considered as includible. References of included works were also evaluated.

The abstracts/full texts of all the studies that emerged from the search were compared to the inclusion criteria. The study search and selection process is schematised in the flow diagram shown in figure 1 . The selection of documents that met the inclusion criteria was independently conducted by three reviewers (S. Vidali, M.L.E. Luisi and E. Cossu).

\section{Quality assessment and data extraction}

Overall quality was evaluated using the Newcastle-Ottawa Scale (NOS) [13], which includes items about selection, comparability and outcome/exposure. The NOS score ranges from 0 to 9 for cohort and case-control studies; publications with a score $\geqslant 6$ were considered of good quality. For cross-sectional studies the NOS score ranges from 0 to 10 ; a score $\geqslant 7$ points was used to identify studies with good quality. The evaluation was performed by three independent reviewers (S. Pancani, D. Morosetti and G. Consales).

A data extraction scheme was designed to address the search questions of this review, consisting of the title of the article, authors, study aim, sample size, mean/median age and sex composition of samples, reference to the mean/median values measured for the D-dimer variable, eventual comparative elaboration and significance, and main findings of the study. The extracted data were compiled into a Microsoft Excel spreadsheet.

Selection bias reduction was addressed by thoughtfully designing the search protocol. In addition, multiple different keywords were used to ensure that as many articles as possible were included in the review. 

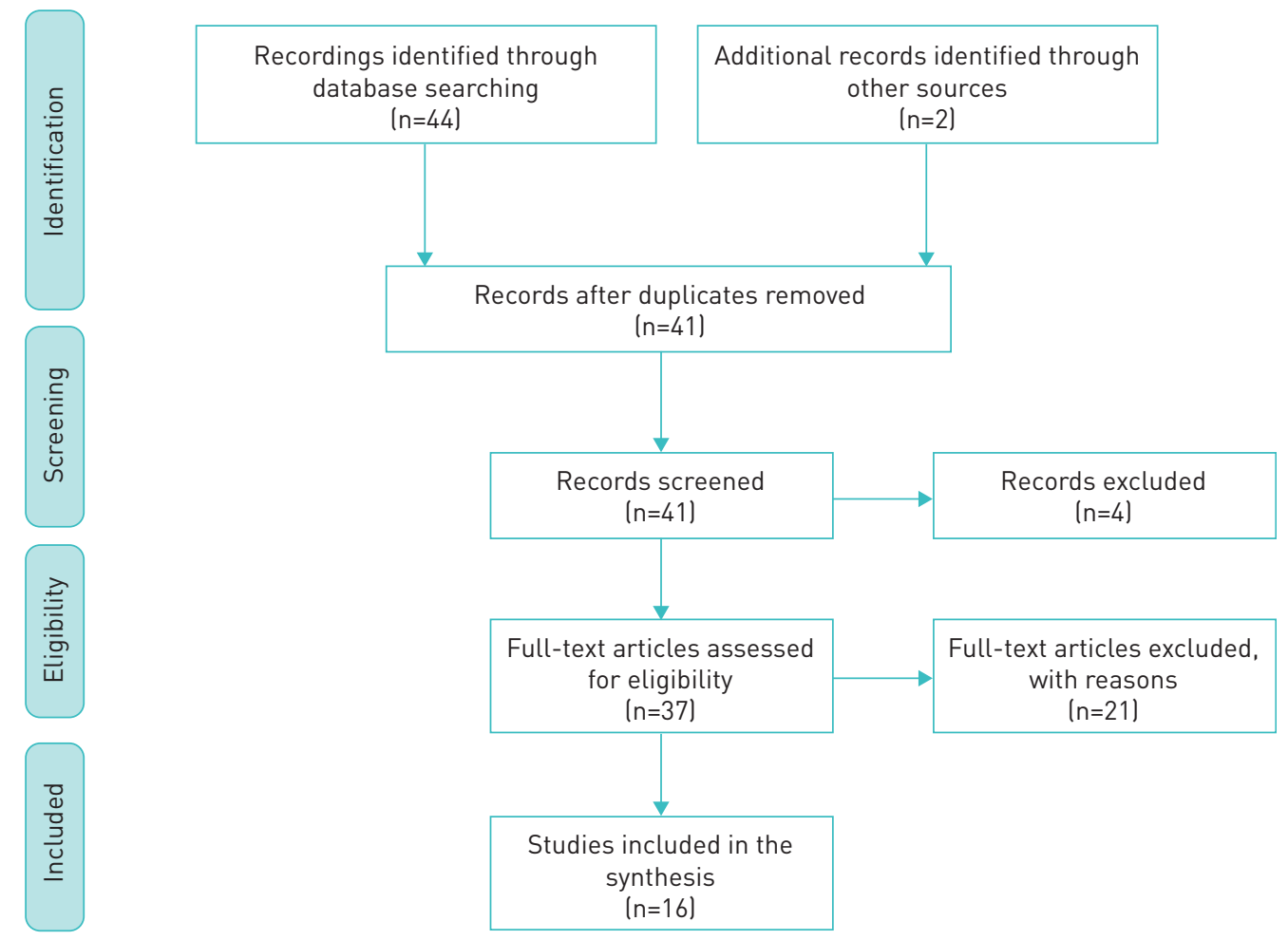

FIGURE 1 Flow diagram of the study search and selection process.

Inaccuracy in document inclusion and data extraction was limited by the work of three reviewers (S. Pancani, D. Morosetti and G. Consales). Disagreements between reviewers were resolved by discussion.

The titles, abstracts and manuscripts of the documents that emerged from the search were analysed. Articles reporting the differences in D-dimer between healed/survived patients and those who reached a CEP or experienced complications such as ARDS, organ failure or multi-organ failure were included.

\section{Results}

From the initial search, 46 studies were collected. After excluding duplicates, 41 studies were identified. Among them, two case reports and two letters to authors were excluded. 20 articles with no explicit mention of $\mathrm{D}$-dimer values and/or differentiation of this parameter among patient subclasses (healed/dead, severe/ non-severe, etc.) were excluded. One article was excluded due to incongruent D-dimer measurement units. 16 articles were then reviewed: 13 between cohort and case-control studies and three cross-sectional, with a variable number of patients enrolled (7-1099). The case-control and cohort studies were demonstrated to reach the criteria for a definition of good quality (all scored $\geqslant 6$ ); however, the cross-sectional studies did not (none scored $\geqslant 7$ points). The quality assessment results are illustrated in table 1 .

The demographic characteristics and rates of comorbidities, ICU admission, complications and death related to the included studies are reported in table 2. The main $\mathrm{D}$-dimer-associated outcome and complication data of the study populations are summarised in table 3.

CHEN et al. [14] (799 COVID-19 patients, among whom the characteristics were analysed of 274 healed and 13 deceased) found markedly higher D-dimer levels in the deceased group during hospitalisation than in survivors $\left(4.6 \mu \mathrm{g} \cdot \mathrm{mL}^{-1}\right.$ versus $\left.0.6 \mu \mathrm{g} \cdot \mathrm{mL}^{-1}\right)$; in addition, $35 \%$ of deceased patients versus $2 \%$ of survivors had D-dimer levels $>21 \mu \mathrm{g} \cdot \mathrm{mL}^{-1}$.

Among the patients evaluated by GUAN et al. [3] (1099 COVID-19 patients, 67 CEP, 15 deceased), in those who reached the CEP, D-dimer levels were $\geqslant 0.5 \mathrm{mg} \cdot \mathrm{L}^{-1}$ in 34 out of 49 analysed cases $(69.4 \%$; versus $44.2 \%$ in non-CEP). Moreover, D-dimer levels were $\geqslant 0.5 \mathrm{mg} \cdot \mathrm{L}^{-1}$ in 65 out of 109 severe cases $(59.6 \%$; versus $43.2 \%$ in non-severe ones).

In the work of HaN et al. [15] (94 COVID-19 patients, 40 healthy controls), among the infected group, during hospitalisation, mean \pm SD $\mathrm{D}$-dimer levels were higher than in the control group $\left(10.36 \pm 25.31 \mathrm{mg} \cdot \mathrm{L}^{-1}\right.$ versus $\left.0.26 \pm 0.18 \mathrm{mg} \cdot \mathrm{L}^{-1} ; \mathrm{p}<0.001\right)$. D-dimer levels appeared to increase with disease 


\begin{tabular}{|c|c|c|c|c|}
\hline First author [ref.] & Selection ${ }^{\#}$ & Comparability" & Outcome/exposure $^{+}$ & Total score s $^{\S}$ \\
\hline \multicolumn{5}{|c|}{ Cohort/case-control } \\
\hline Chen [14] & 4 & 0 & 3 & 7 \\
\hline GUAN [3] & 4 & 0 & 3 & 7 \\
\hline $\mathrm{H}_{\mathrm{AN}}[15]$ & 4 & 0 & 3 & 7 \\
\hline HUANG [1] & 4 & 0 & 3 & 7 \\
\hline TANG [16] & 4 & 0 & 3 & 7 \\
\hline TANG [17] & 4 & 0 & 3 & 7 \\
\hline WANG [18] & 4 & 0 & 3 & 7 \\
\hline WANG [19] & 4 & 2 & 3 & 9 \\
\hline Wu [6] & 4 & 0 & 3 & 7 \\
\hline YIN [20] & 3 & 0 & 3 & 6 \\
\hline ZHANG [21] & 4 & 0 & 3 & 7 \\
\hline Zнои [22] & 4 & 2 & 3 & 9 \\
\hline ZhANG [23] & 3 & 0 & 3 & 6 \\
\hline \multicolumn{5}{|l|}{ Cross-sectional } \\
\hline ZHANG [24] & 4 & 0 & 2 & 6 \\
\hline LI [25] & 3 & 0 & 2 & 5 \\
\hline WAN [26] & 4 & 0 & 2 & 6 \\
\hline
\end{tabular}

severity: those with ordinary (mild) disease had $2.14 \pm 2.88 \mathrm{mg} \cdot \mathrm{L}^{-1}(\mathrm{p}<0.001$ versus controls), those with severe disease had $19.1 \pm 35.48 \mathrm{mg} \cdot \mathrm{L}^{-1} \quad(\mathrm{p}<0.01$ versus controls), and those with critical disease had $20.04 \pm 32.39 \mathrm{mg} \cdot \mathrm{L}^{-1}$. The difference between ordinary and severe disease was significant $(\mathrm{p}<0.05)$.

HuANG et al. [1] (41 COVID-19 patients, 13 admitted to ICU care) described significantly higher D-dimer levels in ICU compared to non-ICU patients $\left(2.4 \mathrm{mg} \cdot \mathrm{L}^{-1}\right.$, range $0.6-14.4 \mathrm{mg} \cdot \mathrm{L}^{-1}$ versus $0.5 \mathrm{mg} \cdot \mathrm{L}^{-1}$, range $\left.0.3-0.8 \mathrm{mg} \cdot \mathrm{L}^{-1} ; \mathrm{p}=0.0042\right)$.

TANG et al. [16] (449 COVID-19 patients, 94 received 40-60 mg.day ${ }^{-1}$ enoxaparin and five received 10000-15000 U.day ${ }^{-1}$ of unfractionated heparin) found that the 28-day mortality of heparin users was lower than that of non-users, in patients who had increased D-dimer values $\left(>3 \mu \mathrm{g} \cdot \mathrm{mL}^{-1}\right.$, six-fold higher

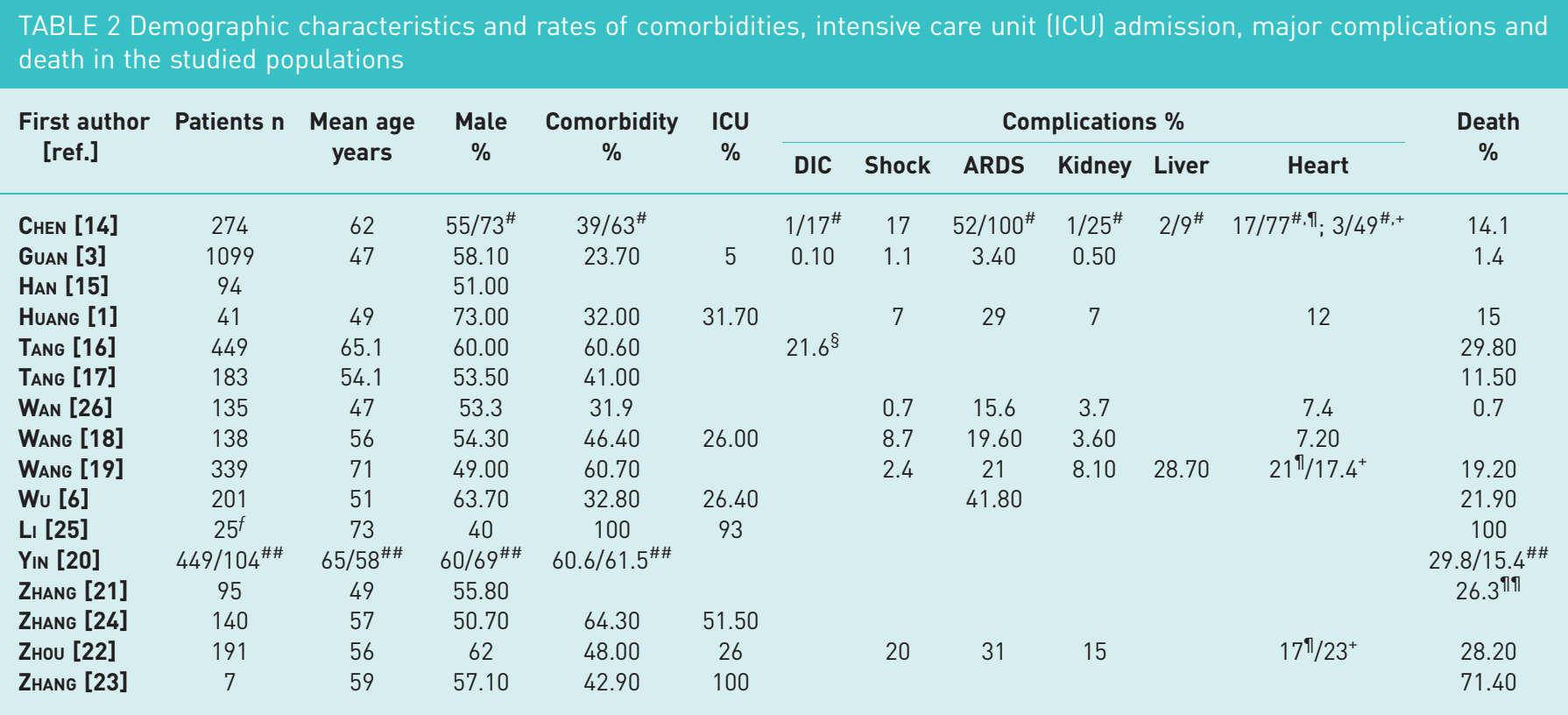

DIC: disseminated intravascular coagulation; ARDS: acute respiratory distress syndrome. ${ }^{\#}:$ recovered/non-recovered; ${ }^{\text {१: }}$ acute cardiac injury;

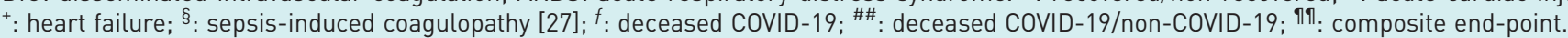


TABLE 3 Outcome and complication differences in the studied populations based on D-dimer levels

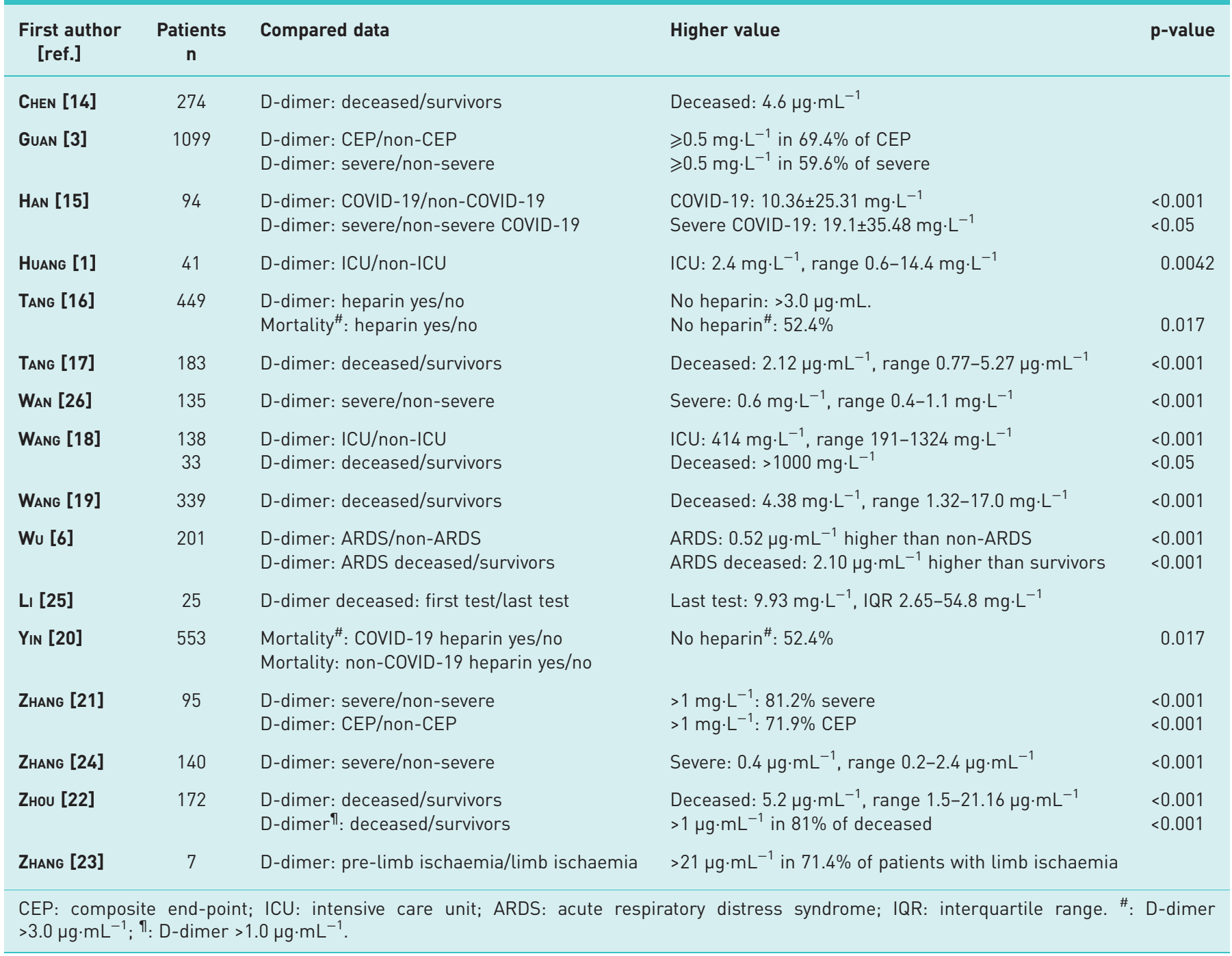

than the normal upper limit). Mortality rates did not differ among heparin users according to D-dimer values; however, mortality was raised alongside the increase in D-dimer in non-users. When the D-dimer levels reached six-fold the normal upper limit, a reduction of $20 \%$ in the mortality rate was found in heparin users compared to non-users (32.8\% versus $52.4 \%$; $\mathrm{p}=0.017)$.

In the work of TANG et al. [17] (183 COVID-19 patients, 21 dead), at admission, mean D-dimer levels in non-survivors were significantly higher compared to survivors and the total population $\left(2.12 \mu \mathrm{g} \cdot \mathrm{mL}^{-1}\right.$, range $0.77-5.27 \mu \mathrm{g} \cdot \mathrm{mL}^{-1}$ versus $0.66 \mu \mathrm{g} \cdot \mathrm{mL}^{-1}$, range $0.38-1.50 \mu \mathrm{g} \cdot \mathrm{mL}^{-1}$ and $0.61 \mu \mathrm{g} \cdot \mathrm{mL}^{-1}$, range $0.35-1.29 \mu \mathrm{g} \cdot \mathrm{mL}^{-1}$, respectively; $\mathrm{p}<0.001$ ).

WAN et al. [26] describe 135 COVID-19 patients: 95 (75.4\%) with mild and 40 (29.6\%) with severe disease. Severe cases had higher D-dimer mean values compared with mild ones $\left(0.6 \mathrm{mg} \cdot \mathrm{L}^{-1}\right.$, range $0.4-1.1 \mathrm{mg} \cdot \mathrm{L}^{-1}$ versus $0.3 \mathrm{mg} \cdot \mathrm{L}^{-1}$, range $0.2-0.5 \mathrm{mg} \cdot \mathrm{L}^{-1}$, respectively; $\mathrm{p}<0.001$ ).

In the study by WANG et al. [18] (138 COVID-19 patients, 36 admitted to ICU), D-dimer levels were higher in ICU than in non-ICU patients $\left(414 \mathrm{mg} \cdot \mathrm{L}^{-1}\right.$, range $191-1324 \mathrm{mg} \cdot \mathrm{L}^{-1}$, versus $166 \mathrm{mg} \cdot \mathrm{L}^{-1}$, range 101-285 mg. $\left.\mathrm{L}^{-1} ; \mathrm{p}<0.001\right)$. An additional evaluation on 33 patients with complete data collection was made: D-dimer levels increased until death and were higher compared to those of survivors (D-dimer levels at 13 days from admission into the ICU were $>1000 \mathrm{mg} \cdot \mathrm{L}^{-1}$ in non-survivors versus $<500 \mathrm{mg} \cdot \mathrm{L}^{-1}$ in survivors; $\mathrm{p}<0.05)$.

WANG et al. [19] (339 elderly COVID-19 patients, mean \pm SD age $71 \pm 8$ years, 80 critical, 159 severe, 100 moderate disease, $65 \mathrm{dead}$ ) found $\mathrm{D}$-dimer levels significantly higher in the deceased compared to 
survivors $\left(4.38 \mathrm{mg} \cdot \mathrm{L}^{-1}\right.$, range $1.32-17.0 \mathrm{mg} \cdot \mathrm{L}^{-1}$ versus $1.08 \mathrm{mg} \cdot \mathrm{L}^{-1}$, range $\left.0.52-2.05 \mathrm{mg} \cdot \mathrm{L}^{-1} ; \mathrm{p}<0.001\right)$. In univariate Cox regression for prognostic factors, D-dimer had a hazard ratio of 1.016 (95\% CI $1.009-1.022$ ) with $\mathrm{p}<0.001$.

In the article by Wu et al. [6] (201 patients, 41.8\% with ARDS, among these $52.4 \%$ deceased), D-dimer values in ARDS patients were significantly higher compared with non-ARDS patients (difference between the two groups $0.52 \mu \mathrm{g} \cdot \mathrm{mL}^{-1}, 95 \%$ CI $0.21-0.94 \mu \mathrm{g} \cdot \mathrm{mL}^{-1} ; \mathrm{p}<0.001$ ). In ARDS patients who died, D-dimer levels were significantly higher compared with ARDS patients who survived (difference between the two groups $2.10 \mu \mathrm{g} \cdot \mathrm{mL}^{-1}, 95 \%$ CI $0.89-5.27 \mu \mathrm{g} \cdot \mathrm{mL}^{-1}$; $\mathrm{p}<0.001$ ). In the bivariate Cox regression analysis for risk factors, D-dimer was significantly associated with ARDS and progression from ARDS to death (hazard ratio $1.03,95 \%$ CI $1.01-1.04 ; \mathrm{p}<0.002$ ).

Li et al. [25] retrospectively reviewed data from 25 deceased COVID-19 patients, showing D-dimer level elevation at the last measurement before death in $75 \%$ of analysed patients, compared to admission values (median D-dimer level at admission $1.18 \mathrm{mg} \cdot \mathrm{L}^{-1}$, interquartile range (IQR) $0.42-4.04 \mathrm{mg} \cdot \mathrm{L}^{-1}$ versus $9.93 \mathrm{mg} \cdot \mathrm{L}^{-1}$, IQR $2.65-54.8 \mathrm{mg} \cdot \mathrm{L}^{-1}$ before death).

In the work of YIN et al. [20] (449 severe COVID-19 and 104 severe non-COVID-19 pneumonia), 99 (22\%) COVID-19 patients received heparin treatment (94 received 40-60 mg.day ${ }^{-1}$ enoxaparin and five received 10000-15000 U.day ${ }^{-1}$ unfractionated heparin) and 22 (21.2\%) non-COVID-19 patients received heparin treatment (20 received 40-60 mg.day ${ }^{-1}$ enoxaparin and two received $10000-15000 \mathrm{U} \cdot$ day $^{-1}$ unfractionated $^{-10}$ heparin). No difference in the 28-day mortality between COVID-19 heparin users and non-users was found. When D-dimer was $>3.0 \mu \mathrm{g} \cdot \mathrm{mL}^{-1}$, mortality was significantly lower in COVID-19 heparin users compared to COVID-19 non-users ( $32.8 \%$ versus $52.4 \%$; $\mathrm{p}=0.017$ ), while no mortality difference was detected between non-COVID-19 heparin users and non-users.

In the study of ZHANG et al. [21] (95 COVID-19 patients with no documented comorbidity, of whom 32 severe, 63 non-severe, and $25 \mathrm{CEP}, 70$ non-CEP), patients were stratified according to D-dimer levels in two groups: $\leqslant 1 \mathrm{mg} \cdot \mathrm{L}^{-1}$ and $>1 \mathrm{mg} \cdot \mathrm{L}^{-1}$. In the $\leqslant 1 \mathrm{mg} \cdot \mathrm{L}^{-1}$ group, $9.5 \%$ of cases were severe and $3.2 \%$ achieved the CEP, while in the $>1 \mathrm{mg} \cdot \mathrm{L}^{-1}$ group, $81.2 \%$ of cases were severe and $71.9 \%$ achieved the CEP (both $\mathrm{p}<0.001$ ). Elevation of D-dimer level was strongly associated with severe forms of COVID-19 pneumonia and with the presence of a CEP (both $\mathrm{p}<0.001$ ).

ZHANG et al. [24] (140 COVID-19 patients, 58 severe, 82 non-severe) reported significantly higher mean $\mathrm{D}$-dimer values in severe compared to non-severe cases $\left(0.4 \mu \mathrm{g} \cdot \mathrm{mL}^{-1}\right.$, range $0.2-2.4 \mu \mathrm{g} \cdot \mathrm{mL} \mathrm{L}^{-1}$ versus $0.2 \mu \mathrm{g} \cdot \mathrm{mL}^{-1}$, range $\left.0.1-0.3 \mu \mathrm{g} \cdot \mathrm{mL}^{-1} ; \mathrm{p}<0.001\right)$.

In the work of ZHou et al. [22] (191 COVID-19 patients, 137 survivors, 54 non-survivors), the mean D-dimer levels of 172 patients from the study population were significantly higher in non-survivors compared to survivors $\left(5.2 \mu \mathrm{g} \cdot \mathrm{mL}^{-1}\right.$, range $1.5-21.16 \mu \mathrm{g} \cdot \mathrm{mL}^{-1}$ versus $0.6 \mu \mathrm{g} \cdot \mathrm{mL}^{-1}$, range $0.3-1.06 \mu \mathrm{g} \cdot \mathrm{mL}^{-1}$; $\mathrm{p}<0.0001$ ), with values $>1 \mu \mathrm{g} \cdot \mathrm{mL}^{-1}$ in $81 \%$ of non-survivors versus $24 \%$ of survivors, values of $0.5-1 \mu \mathrm{g} \cdot \mathrm{mL}^{-1}$ in $11 \%$ of non-survivors versus $33 \%$ of survivors, and values $<0.5 \mu \mathrm{g} \cdot \mathrm{mL}^{-1}$ in $7 \%$ of non-survivors versus $43 \%$ of survivors. In univariable and multivariable logistic variation analysis, $\mathrm{D}$-dimer levels $>1 \mu \mathrm{g} \cdot \mathrm{mL}^{-1}$ were associated with increased odds of in-hospital death (univariable analysis showed odds ratio $20.04 \mu \mathrm{g} \cdot \mathrm{mL}^{-1}$, 95\% CI $6.52-61.56 \mu \mathrm{g} \cdot \mathrm{mL}^{-1}, \quad \mathrm{p}<0.0001$; multivariable analysis showed odds ratio $18.42 \mu \mathrm{g} \cdot \mathrm{mL}^{-1}, 95 \%$ CI $\left.2.64-128.55 \mu \mathrm{g} \cdot \mathrm{mL}^{-1}, \mathrm{p}=0.0033\right)$.

In the work of ZHANG et al. [23] (seven COVID-19 ICU patients, who developed critical limb ischaemia), mean D-dimer levels at ICU admission were $7.3 \mu \mathrm{g} \cdot \mathrm{mL}^{-1}$ (range $1.25-21.00 \mu \mathrm{g} \cdot \mathrm{mL}^{-1}$ ). At the time of limb ischaemia occurrence, median D-dimer increased to $>20$-fold the normal range and in five patients (71.4\%) it exceeded the limit of detection $\left(>21 \mu \mathrm{g} \cdot \mathrm{mL}^{-1}\right)$. After 3-5 days of anticoagulants, D-dimer levels decreased, but remained above the upper limit of normal $\left(0.5 \mu \mathrm{g} \cdot \mathrm{mL}^{-1}\right)$ in all patients (lowest value $\left.3.36 \mu \mathrm{g} \cdot \mathrm{mL}^{-1}\right)$. Among the seven patients, those meeting the DIC diagnosis criteria [27] passed from $0 \%$ at admission to $57.14 \%$ at the time of thrombosis, to $42.8 \%$ after anticoagulant therapy [23].

\section{Discussion}

Hypercoagulability, injury of the endothelium and venous stasis, defining the Virchow triad, represent the cardinal inducers of thrombus formation. Conditions predisposing to thrombosis directly or indirectly involve mechanisms associated with this triad [28]. The role of inflammation and hypoxia, among the pathogenetic pathways of hypercoagulative states and thrombosis, has been extensively studied [29-33]. It has been demonstrated that inflammatory settings, where the release of cytokines such as interleukin (IL)-1, tumour necrosis factor (TNF)- $\alpha$ and complement factors is consistent, induce an upregulation of plasminogen activator inhibitor (PAI)-1 with consequent impairment of fibrinolysis. Moreover, they cause pro-inflammatory changes of endothelial cells that increase the expression of chemoattractants and 
adhesion molecules necessary for mononucleate activation and extravascular transformation in macrophages [11, 30, 34-36]. Mononucleate cells are stimulated by circulating cytokines to produce tissue factor, trigger and initiator of coagulative extrinsic cascades [30, 37]. In addition, pro-inflammatory cytokines such as IL- 6 and IL-8, and platelets themselves, induce platelet activation and cooperate in the propagation and maintaining of coagulative mechanisms $[35,38]$.

Products of coagulation eventually perpetuate inflammatory pathways through a stimulation of leukocytes, which enhances the production of cytokines such as IL-1 and IL-6, therefore indirectly perpetrating coagulative mechanisms $[35,39]$.

In a positive loop of reciprocal induction, hypoxia not only is a consequence of vascular occlusion, but can also stimulate thrombus formation and propagation, through the activation of multiple cellular and molecular pathways. These include hypoxia-inducible factors (HIFs), more precisely HIF1 and HIF2 [30, 40, 41]. In hypo-oxygenation, nuclear dimerisation of HIFs is extremely enhanced, with consequent activation of hypoxia responsive element and transcription of genes coding for molecules directly implicated in coagulative homeostasis such as PAI-1 [28, 42]. Hypoxia also induces the production of molecules such as early growth response-1, TNF- $\alpha$, IL-1 and other regulators of thrombus formation and reduces that of thrombomodulin, therefore inducing pro-thrombotic changes and progressively reducing the fibrinolytic activity of the endothelium $[28,43,44]$.

During sepsis, multiple factors enhancing coagulation are activated. The pathogen-related cellular damage and immune responses stimulate the production of molecules such as the pathogen-associated molecular patterns (PAMPs). PAMPs induce the release from damaged cells of DNA, histones and pattern-recognising receptors, promoters of both inflammation and coagulation $[45,46]$. Other mediators implicated are represented by neutrophil extracellular traps (NETs). When activated by pathogens such as viruses or stimulated by molecules such as endothelial P-selectin, neutrophils can induce NETosis, a specific kind of apoptosis. NETosis results in the production of extracellular proteins, histones and DNA-intertwined compounds implicated in hypercoagulative states by acting as a scaffold for thrombus formation [46].

Pathogenetic mechanisms of SARS-CoV-2 infections involve the binding of virus envelope glycoprotein to ACE2 [10, 11]. ACE2 can be identified on the cells of multiple tissues, particularly alveolar epithelial, endothelial, intestinal epithelial and others [23]. The innate tropism for vascular endothelial cells and their consequent damage, together with the intense activation of inflammatory responses and of coagulation pathways, may explain the intense pro-coagulative state [47]. This predisposes to systemic micro-thrombotic alterations and may give a partial explanation to the consistent rate of multi-organ failure, DIC and, based on the consistent involvement of lung structures, of ARDS in severe COVID-19 patients.

D-dimer is an indirect marker of active coagulation and thrombin formation. It is in fact released when plasmin, a fibrinolytic enzyme, cleaves fibrin to degrade clots and represents a mirror of the endovascular thrombotic processes [48].

The alterations of coagulation factors during SARS-CoV-2 infection and specifically that of D-dimer are, as documented in the clinical experiences described here, severe, constant and correlated with prognosis, complications and CEP rates. As reported by TANG et al. [17], mean D-dimer levels in non-survivors were significantly higher compared to survivors and, based on the experience of WANG et al. [18], those levels continue to increase until death with higher values compared to survivors. Additionally, D-dimer appears significantly higher in severe patients compared to non-severe ones, as shown in the study by ZHANG et al. [24]. Similar results were obtained by HUANG et al. [1], where they classified patients based on whether they were admitted to the ICU.

Among the factors that were demonstrated to be connected to the clinical outcome of COVID-19 patients, the presence of comorbidities may represent a confounding factor for the interpretation of D-dimer and other coagulation parameter alterations, especially considering the heterogeneous aetiology of thrombotic and thrombophilic states. However, as emerged from the article by ZHANG et al. [21], elevations of D-dimer levels were strongly associated with severe forms of COVID-19 and with the presence of a CEP (both $\mathrm{p}<0.001$ ). Also, in the work of HAN et al. [15], mean D-dimer levels in COVID-19 patients were significantly higher than those in the healthy control group $(\mathrm{p}<0.001)$ and increased substantially with the severity of the disease.

This hypercoagulative infection-induced state is, as previously mentioned, systemic, and may lead to various clinical manifestations such as limb ischaemia (as documented by ZHANG et al. [23]), DIC and, progressively, to coagulation factor deterioration [49]. However, due to the more consistent tropism of this virus for lung structures, micro- and macro-thrombotic events in this organ should be primarily considered. These conditions represent severe therapeutic challenges and may require non-pharmacological, invasive 
rescue treatments, such as endovascular interventional ones. These represent an extra vigorous stress on already very fragile patients.

In the experience of $\mathrm{Wu}_{\mathrm{U}}$ et al. [6], D-dimer levels in COVID-19 patients with ARDS were significantly higher compared to those without ARDS, and those of deceased ARDS patients were significantly higher than those of ARDS patients who survived, with significant association between D-dimer elevation and the development of ARDS and progression from ARDS to death. In cases with sudden or progressive oxygen level deterioration, ARDS-compatible symptoms, signs of right ventricle progressive overload or diffuse perfusion alterations of micro-thrombotic aetiology, the possibility of pulmonary thromboembolism should be considered [50]. Enforcing this theory, recent pathology studies of deceased COVID-19 patients showed the presence of pulmonary small vessel micro-thrombotic alterations [51, 52]. Although a cost-benefit evaluation of the appropriateness of each medical action should always be performed to reduce infection transmission risk (pulmonary ventilation/perfusion examinations are, for this reason, not recommended), in cases of $\mathrm{D}$-dimer progressive elevation, decay of respiratory gas exchange, as well as progressive signs of right side congestive heart failure, the hypothesis of a diagnostic investigation with pulmonary angio-CT scan should be considered, in order to promptly detect possible pulmonary embolic states and to perform adequate pharmacological interventions [53-55].

Similarly, in cases of parenchymal function deterioration, limb ischaemic manifestations or matching of DIC or sepsis-induced coagulopathy criteria [27], parenchymal and peripheral vascular Dopplerultrasound evaluation would be useful, allowing the identification and treatment of eligible patients [56].

The association between SARS-CoV-2 infection and coagulation changes is becoming more defined and experience with anticoagulants, especially low-molecular-weight heparin (LMWH), as COVID-19 management drugs is progressively increasing [54, 55]. As reported in the study by TANG et al. [16], the 28-day mortality of patients with markedly high $\mathrm{D}$-dimer levels treated with therapeutic doses of heparin was lower than that of non-treated patients, with mortality rates that were raised in non-users together with the increase of D-dimer. Similarly, YIN et al. [20] described no difference in the 28-days mortality between COVID-19 heparin users and non-users overall. However, when D-dimer was $>3.0 \mu \mathrm{g} \cdot \mathrm{mL}^{-1}$, mortality was significantly lower in COVID-19 heparin users compared to COVID-19 non-users $(\mathrm{p}=0.017)$, while no mortality difference was detected between non-COVID-19 heparin users and non-users.

Anticoagulant therapy therefore represents a valid tool to use in the rehabilitation of the very fragile global homeostasis of the COVID-19 population and has proved its benefits when administered considering patients' clinical characteristics and contraindications [16, 20,57, 58]. However, the appropriate time to start therapeutic administration of these drugs, especially aiming to intervene before patients become symptomatic due to major thrombosis-related dysfunction, has not yet been defined.

The hypothesis of an early and continuous pro-thrombotic activity of SARS-CoV-2 and therefore the appropriateness of an immediate and continuous monitoring of coagulation indicators, such as D-dimer, with consequent labelled administration of adjusted doses of anticoagulants, should be addressed further, in order to prevent worsening of global conditions due to vascular parenchymal or systemic thrombotic dysfunction.

As indicated by HunT et al. [54] and ZHou et al. [55], prophylactic anticoagulant treatment with LMWH is to be considered, always after making a precise risk stratification (i.e. tracheostomy access management) and an evaluation of possible contraindications (recent or forthcoming surgery, active bleedings, etc.). However, the precise investigation of the correct balance between D-dimer elevation, coagulation asset and doses of anticoagulants, especially in pre-symptomatic conditions, during COVID-19 disease, has not yet been performed and would be of great interest, in order to personalise treatments, to allow a graduated and targeted adjustment of doses, therefore preventing disease-related thrombotic complications and drug-induced severe coagulation disorders.

To conclude, after evaluating clinical data reported in the literature, SARS-CoV-2-induced coagulation alterations and consequent micro- and macro-thrombotic events appeared to be an issue of primary importance. This is particularly supported by the evidence of severe elevation of D-dimer levels observed in critically ill COVID-19 patients. Treatment schemes with anticoagulant drugs, especially heparin and LMWH, based on monitoring the levels of D-dimer and other coagulation factors, should be further addressed in order to define adequate timing (therapeutic and prophylactic) and efficacy, based on patients' characteristics, clinical presentations and coagulative function.

Limitations to this work were represented by the actuality of the investigated issue: available data sources are recent and therefore the knowledge on the disease's implication is not global. Additionally, both the studies designed specifically to investigate the implications of coagulation and D-dimer in COVID-19 
disease and those reporting explicit D-dimer-related data vary widely in terms of measurement protocols and of the investigated D-dimer-related outcomes. Despite the presence of these limitations, which are substantially related to the recent presentation of COVID-19, the examination and re-elaboration of data from clinical observations seems fundamental, in order to highlight infection-related major issues and to consequently produce evidence-based management and therapeutic solutions.

Author contributions: S. Vidali: conception, design of the work, acquisition of data, draft and substantive revision of the work. D. Morosetti: analysis and interpretation of data, substantive revision of the work. E. Cossu: acquisition of data, substantive revision of the work. M.L.E. Luisi: conception, design of the work, acquisition of data, draft and substantive revision of the work. S. Pancani: analysis and interpretation of data, substantive revision of the work. V. Semeraro: design of the work, substantive revision of the work. G. Consales: conception, design of the work, substantive revision of the work. All have approved the submitted version (and any substantially modified version that involves the author's contribution to the study). All have agreed both to be personally accountable for the authors' own contributions and to ensure that questions related to the accuracy or integrity of any part of the work, even ones in which the author was not personally involved, are appropriately investigated, resolved, and the resolution documented in the literature.

Conflict of interest: None declared.

\section{References}

1 Huang C, Wang Y, Li X, et al. Clinical features of patients infected with 2019 novel coronavirus in Wuhan, China. Lancet 2020; 395: 497-506.

2 Driggin E, Madhavan MV, Bikdeli B, et al. Cardiovascular considerations for patients, health care workers, and health systems during the COVID-19 pandemic. J Am Coll Cardiol 2020; 75: 2352-2371.

3 Guan WJ, Ni ZY, Hu Y, et al. Clinical characteristics of coronavirus disease 2019 in China. N Engl J Med 2020; 382: $1708-1720$.

4 McMichael TM, Currie DW, Clark S, et al. Epidemiology of COVID-19 in a long-term care facility in King County, Washington. N Engl J Med 2020; 382: 2005-2011.

5 World Health Organization. Coronavirus disease 2019 (COVID-19) Situation Report-85. 14 April 2020. www. who.int/docs/default-source/coronaviruse/situation-reports/20200414-sitrep-85-covid-19.pdf

$6 \mathrm{Wu} \mathrm{C}$, Chen $\mathrm{X}$, Cai Y, et al. Risk factors associated with acute respiratory distress syndrome and death in patients with coronavirus disease 2019 pneumonia in Wuhan, China. JAMA Intern Med 2020; in press [https://doi.org/10. 1001/jamainternmed.2020.0994].

7 World Health Organization. Clinical management of severe acute respiratory infection (SARI) when COVID-19 disease is suspected: interim guidance, 13 March 2020. https://apps.who.int/iris/handle/10665/331446

8 Ng DL, Al Hosani F, Keating MK, et al. Clinicopathologic, immunohistochemical, and ultrastructural findings of a fatal case of Middle East respiratory syndrome coronavirus infection in the United Arab Emirates, April 2014. Am J Pathol 2016; 186: 652-658.

9 Nicholls JM, Poon LLM, Lee KC, et al. Lung pathology of fatal severe acute respiratory syndrome. Lancet 2003; 361: 1773-1778.

10 Zhang H, Penninger JM, Li Y, et al. Angiotensin-converting enzyme 2 (ACE2) as a SARS-CoV-2 receptor: molecular mechanisms and potential therapeutic target. Intensive Care Med 2020; 46: 586-590.

11 Wan Y, Shang J, Graham R, et al. Receptor recognition by the novel coronavirus from Wuhan: an analysis based on decade-long structural studies of SARS coronavirus. J Virol 2020; 94: e00127-20.

12 Madjid M, Safavi-Naeini P, Solomon SD, et al. Potential effects of coronaviruses on the cardiovascular system: a review. JAMA Cardiol 2020; in press [https://doi.org/10.1001/jamacardio.2020.1286].

13 Wells GA, Shea B, O'Connell D, et al. The Newcastle-Ottawa Scale (NOS) for assessing the quality of nonrandomised studies in meta-analyses. Ottawa, Ottawa Hospital Research Institute, 2011. Available from: www. ohri.ca/programs/clinical_epidemiology/oxford.asp

14 Chen $\mathrm{T}, \mathrm{Wu} \mathrm{D}$, Chen $\mathrm{H}$, et al. Clinical characteristics of 113 deceased patients with coronavirus disease 2019: retrospective study. BMJ 2020; 368: $\mathrm{m} 1091$.

15 Han H, Yang L, Liu R, et al. Prominent changes in blood coagulation of patients with SARS-CoV-2 infection. Clin Chem Lab Med 2020; 25: 1116-1120.

16 Tang $\mathrm{N}$, Bai $\mathrm{H}$, Chen $\mathrm{X}$, et al. Anticoagulant treatment is associated with decreased mortality in severe coronavirus disease 2019 patients with coagulopathy. J Thromb Haemost 2020; 18: 1094-1099.

17 Tang N, Li D, Wang X, et al. Abnormal coagulation parameters are associated with poor prognosis in patients with novel coronavirus pneumonia. J Thromb Haemost 2020; 18: 844-847.

18 Wang $\mathrm{D}, \mathrm{Hu} \mathrm{B}, \mathrm{Hu} \mathrm{C}$, et al. Clinical characteristics of 138 hospitalized patients with 2019 novel coronavirus-infected pneumonia in Wuhan, China. JAMA 2020; 323: 1061-1069.

19 Wang L, He W, Yu X, et al. Coronavirus disease 2019 in elderly patients: characteristics and prognostic factors based on 4-week follow-up. J Infect 2020; 80: 639-645.

20 Yin S, Huang M, Li D, et al. Difference of coagulation features between severe pneumonia induced by SARS-CoV2 and non-SARS-CoV2. J Thromb Thrombolysis 2020; in press [https://doi.org/10.1007/s11239-020-02105-8].

21 Zhang G, Zhang J, Wang B, et al. Analysis of clinical characteristics and laboratory findings of 95 cases of 2019 novel coronavirus pneumonia in Wuhan, China: a retrospective analysis. Respir Res 2020; 21: 74.

22 Zhou F, Yu T, Du R, et al. Clinical course and risk factors for mortality of adult inpatients with COVID-19 in Wuhan, China: a retrospective cohort study. Lancet 2020; 395: 1054-1062.

23 Zhang Y, Cao W, Xiao M, et al. Clinical and coagulation characteristics in 7 patients with critical COVID-2019 pneumonia and acro-ischemia. Chin J Hematol 2020; 41: 302-307.

24 Zhang JJ, Dong X, Cao YY, et al. Clinical characteristics of 140 patients infected with SARS-CoV-2 in Wuhan, China. Allergy 2020; in press [https://doi.org/10.1111/all.14238]. 

medical records in a single medical center, Wuhan, China. Int I Infect Dis 2020; 94: 128-132.

26 Wan S, Xiang Y, Fang W, et al. Clinical features and treatment of COVID-19 patients in northeast Chongqing J Med Virol 2020; 92: 797-806.

27 Iba T, Nisio MD, Levy JH, et al. New criteria for sepsis-induced coagulopathy (SIC) following the revised sepsis definition: a retrospective analysis of a nationwide survey. BMJ Open 2017; 7: e017046.

28 Gupta N, Zhao YY, Evans CE. The stimulation of thrombosis by hypoxia. Thromb Res 2019; 181: 77-83.

29 Eltzschig HK, Carmeliet P. Hypoxia and inflammation. N Engl J Med 2011; 364: 656-665.

30 Poterucha TJ, Libby P, Goldhaber SZ. More than an anticoagulant: do heparins have direct anti-inflammatory effects? Thromb Haemost 2017; 117: 437-444.

31 Kumar DR, Hanlin E, Glurich I, et al. Virchow's contribution to the understanding of thrombosis and cellular biology. Clin Med Res 2010; 8: 168-172.

32 Prchal JT. Hypoxia and thrombosis. Blood 2018; 132: 348-349.

33 Zangari M, Fink L, Tolomelli G, et al. Could hypoxia increase the prevalence of thrombotic complications in polycythemia vera? Blood Coagul Fibrinolysis 2013; 24: 311-316.

34 Libby P, Nahrendorf M, Swirski FK. Leukocytes link local and systemic inflammation in ischemic cardiovascular disease: an expanded "cardiovascular continuum". J Am Coll Cardiol 2016; 67: 1091-1103.

35 Hook KM, Abrams CS. The loss of homeostasis in hemostasis: new approaches in treating and understanding acute disseminated intravascular coagulation in critically ill patients. Clin Transl Sci 2012; 5: 85-92.

36 Mileno MD, Margolis NH, Clark BD, et al. Coagulation of whole blood stimulates interleukin-1 beta gene expression. J Infect Dis 1995; 172: 308-311.

37 Mendoza-Pinto C, García-Carrasco M, Cervera R. Role of infectious diseases in the antiphospholipid syndrome (including its catastrophic variant). Curr Rheumatol Rep 2018; 20: 62.

38 Esmon CT. The impact of the inflammatory response on coagulation. Thromb Res 2004; 114: $321-327$.

39 van der Poll T, de Jonge E, Levi M. Regulatory role of cytokines in disseminated intravascular coagulation. Semin Thromb Hemost 2001; 27: 639-651.

40 Rius J, Guma M, Schachtrup C, et al. NF- $\kappa \mathrm{B}$ links innate immunity to the hypoxic response through transcriptional regulation of HIF-1 $\alpha$. Nature 2008; 453: 807-811.

41 Pugh CW, Ratcliffe PJ. New horizons in hypoxia signaling pathways. Exp Cell Res 2017; 356: $116-121$.

42 Liao H, Hyman MC, Lawrence DA, et al. Molecular regulation of the PAI-1 gene by hypoxia: contributions of Egr-1, HIF-1 $\alpha$, and C/EBP $\alpha$. FASEB J 2007; 21: 935-949.

43 Yan SF, Mackman N, Kisiel W, et al. Hypoxia/hypoxemia-induced activation of the procoagulant pathways and the pathogenesis of ischemia-associated thrombosis. Arterioscler Thromb Vasc Biol 1999; 19: 2029-2035.

44 Ogawa S, Shreeniwas R, Brett J, et al. The effect of hypoxia on capillary endothelial cell function: modulation of barrier and coagulant function. Br J Haematol 1990; 75: 517-524.

45 Iba T, Levy JH, Raj A, et al. Advance in the management of sepsis-induced coagulopathy and disseminated intravascular coagulation. J Clin Med 2019; 8: 728.

46 Ito T. PAMPs and DAMPs as triggers for DIC. J Intensive Care 2014; 2: 67.

47 Liu PP, Blet A, Smyth D, et al. The science underlying COVID-19: implications for the cardiovascular system. Circulation 2020; 142: 68-78

48 Linkins LA, Takach Lapner S. Review of D-dimer testing: good, bad, and ugly. Int J Lab Hematol 2017; 39 Suppl. 1, 98-103.

49 Lillicrap D. Disseminated intravascular coagulation in patients with 2019-nCoV pneumonia. J Thromb Haemost 2020; 18: 786-787.

50 Danzi GB, Loffi M, Galeazzi G, et al. Acute pulmonary embolism and COVID-19 pneumonia: a random association? Eur Heart J 2020; 41: 1858

51 Liu Q, Wang RS, Qu GQ, et al. Gross examination report of a COVID-19 death autopsy. Fa Yi Xue Za Zhi 2020; 36: $21-23$.

52 Luo W, Yu H, Gou J, et al. Clinical pathology of critical patient with novel coronavirus pneumonia (COVID-19). Preprints 2020; preprint [https://www.preprints.org/manuscript/202002.0407].

53 Zuckier LS, Moadel RM, Haramati LB, et al. Diagnostic evaluation of pulmonary embolism during the COVID-19 pandemic. J Nucl Med 2020; 61: 630-631.

54 Hunt B, Retter A, McClintock C. Practical guidance for the prevention of thrombosis and management of coagulopathy and disseminated intravascular coagulation of patients infected with COVID-19. Llanwrda, Thrombosis UK, 2020.

55 Zhou M, Zhang X, Qu J. Coronavirus disease 2019 (COVID-19): a clinical update. Front Med 2020; 14: 126-135.

56 Lim W, Le Gal G, Bates SM, et al. American Society of Hematology 2018 guidelines for management of venous thromboembolism: diagnosis of venous thromboembolism. Blood Adv 2018; 2: 3226-3256.

57 Lippi G, Favaloro EJ. D-dimer is associated with severity of coronavirus disease 2019: a pooled analysis. Thromb Haemost 2020; 120: 876-878.

58 Bikdeli B, Madhavan MV, Jimenez D, et al. COVID-19 and thrombotic or thromboembolic disease: implications for prevention, antithrombotic therapy, and follow-up. J Am Coll Cardiol 2020; 75: 2950-2973. 